\title{
Protocol for the Pregnancy During the COVID-19 Pandemic (PdP) Study: A Longitudinal Cohort Study of Mental Health Among Pregnant Canadians During the COVID-19 Pandemic and Developmental Outcomes in Their Children
}

Gerald F Giesbrecht ${ }^{1,2,3,4}$, PhD; Mercedes Bagshawe ${ }^{5}$, BA; Melinda van Sloten ${ }^{1}, \mathrm{BA}$; Anna L MacKinnon ${ }^{2,3}$, PhD; Ashley Dhillon ${ }^{3}$, BSc; Marcel van de Wouw ${ }^{1}$, PhD; Elnaz Vaghef-Mehrabany ${ }^{1}$, PhD; Laura Rojas ${ }^{1,2}$, BSc; Danielle Cattani $^{1}, \mathrm{BSc}$; Catherine Lebel ${ }^{2,5^{*}}, \mathrm{PhD}$; Lianne Tomfohr-Madsen ${ }^{1,2,3^{*}}, \mathrm{PhD}$

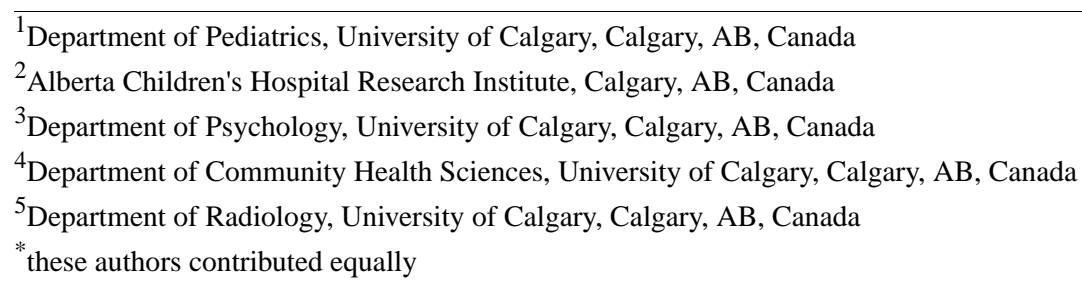

\section{Corresponding Author:}

Gerald F Giesbrecht, PhD

Department of Pediatrics

University of Calgary

2500 University Drive

Calgary, AB, T2N 1N4

Canada

Phone: 14034418469

Email: ggiesbre@ucalgary.ca

\section{Abstract}

Background: The COVID-19 pandemic and countermeasures implemented by governments around the world have led to dramatically increased symptoms of depression and anxiety. Pregnant individuals may be particularly vulnerable to the negative psychological effects of COVID-19 public health measures because they represent a demographic that is most affected by disasters and because pregnancy itself entails significant life changes that require major psychosocial and emotional adjustments.

Objective: The PdP study was designed to investigate the associations among exposure to objective hardship caused by the pandemic, perceived stress and psychological distress in pregnant individuals, and developmental outcomes in their offspring.

Methods: The PdP study comprises a prospective longitudinal cohort of individuals who were pregnant at enrollment, with repeated follow-ups during pregnancy and the postpartum period. Participants were eligible if they were pregnant, $\geq 17$ years old, at $\leq 35$ weeks of gestation at study enrollment, living in Canada, and able to read and write in English or French. At enrollment, participants completed an initial survey that assessed demographic and socioeconomic characteristics, previous pregnancies and births, prepregnancy health, health conditions during pregnancy, medications, psychological distress, social support, and hardships experienced because of the COVID-19 pandemic (eg, lost employment or a loved one dying). For the first three months following the initial survey, participants received a monthly email link to complete a follow-up survey that asked about their experiences since the previous survey. After three months, follow-up surveys were sent every other month to reduce participant burden. For each of these surveys, participants were first asked if they were still pregnant and then routed either to the next prenatal survey or to the delivery survey. In the postpartum period, surveys were sent at 3, 6, and 12 months of infant age to assess maternal stress, psychological distress, and infant development.

Results: Participant recruitment via social media (Facebook and Instagram) began on April 5, 2020, and is ongoing. As of April 2021, more than 11,000 individuals have started the initial survey. Follow-up data collection is ongoing.

Conclusions: This longitudinal investigation seeks to elucidate the associations among hardships, maternal psychological distress, child development during the COVID-19 pandemic, and risk and resilience factors that amplify or ameliorate these 
associations. The findings of this study are intended to generate knowledge about the psychological consequences of pandemics on pregnant individuals and point toward prevention and intervention targets.

International Registered Report Identifier (IRRID)： DERR1-10.2196/25407

(JMIR Res Protoc 2021;10(4):e25407) doi: 10.2196/25407

\section{KEYWORDS}

pregnancy; anxiety; depression; stress; social support; resilience; COVID-19; infant development; pandemic

\section{Introduction}

\section{Background}

In December 2019, the novel SARS-CoV-2 caused an outbreak of COVID-19 in Wuhan, China, which rapidly spread around the world. COVID-19 was declared a global pandemic on March 11, 2020 [1]. Although most people with COVID-19 recover from the disease, the associated morbidity and mortality, as well as the uncertainty surrounding long-term effects, has prompted governments around the world to implement public health measures to slow and reduce the spread of COVID-19. Worldwide, these measures have included recommendations for hand and respiratory hygiene (ie, frequent handwashing; avoiding touching one's eyes, nose, and mouth; coughing or sneezing into a bent elbow), travel restrictions, self-isolation, wearing masks in public, and physical distancing. These measures resulted in dramatic changes in the everyday life for most people, including the ways that people work, socialize, eat, and play. For example, many people were mandated to work from home, and a large number of people lost their jobs (both temporary and permanent) or saw substantial changes in their jobs. Schools and daycare centers were closed, with controversial reopening plans. Hospitals, health care facilities, and care homes limited their services and restricted visitor, caregiver, and support person access to patients and residents. Recreational facilities were closed, and public health recommendations to remain at home for anything other than essentials severely restricted people's opportunities for recreation, physical activity, and socializing. These examples illustrate the disruption across many aspects of everyday life and the potential for uncertainty, worry, and fear that result from public health measures to limit the spread of COVID-19. A timeline of the major public health measures implemented in Canada is illustrated in Figure 1. 
Figure 1. Timeline of COVID-19 events.

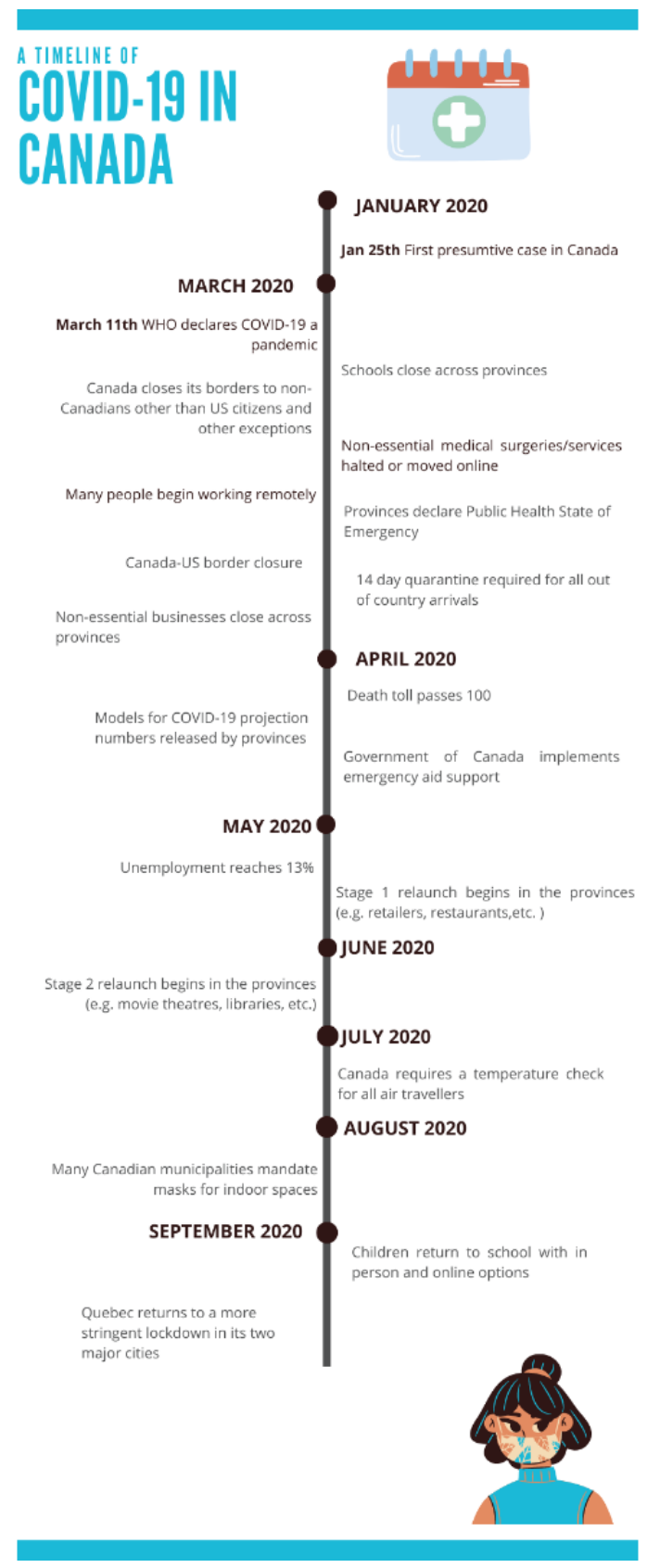

\section{A Need to Understand the Effects of Pandemics on Mental Health}

Although there is evidence that disasters increase symptoms and incidence of mental illness, research on the mental health consequences of epidemics and pandemics is sparse. Existing studies focus on front-line health care workers [2] and the mental health consequences of adjusting to morbidity caused by disease (eg, parents of children with congenital zika virus syndrome) [3]. However, little is known about the psychological effects of pandemic countermeasures such as quarantine, physical distancing, and shelter-in-place orders. A small study of individuals instructed to voluntarily quarantine during the 2003 severe acute respiratory syndrome (SARS) outbreak in Toronto reported elevated symptoms of posttraumatic stress disorder and depression [4]. Postdisaster studies have consistently observed increases in mental health problems following large-scale but localized events such as natural (eg, earthquakes) [5], traumatic (eg, the World Trade Center attacks) [6], and environmental (eg, Chernobyl nuclear disaster) [7] disasters.

Although most individuals will display resilience in the face of disaster, a substantial proportion will experience some psychological impairment and a smaller proportion will develop a mental health disorder [8]. The degree or severity of exposure to disaster consistently and strongly predicts greater postdisaster psychological impairment [9], with additional contributions from factors such as predisaster mental health problems, low socioeconomic status, minority ethnicity, low social support, younger age, caring for children, and personality characteristics such as neuroticism [8]. A national population-based cohort study conducted in the United Kingdom found that minority ethnicity, overweight or obesity, age over 35 years, and pre-existing health conditions increased the risk for severe 
COVID-19 (eg, hospitalization required) among pregnant women [10].

There is growing concern that the public health response to the COVID-19 pandemic has created a shadow pandemic of mental illness. Public polls have repeatedly suggested widespread and dramatically elevated worries related to financial, social, and psychological well-being [11]. For example, 37\% of the respondents of a nationally representative poll in the United States conducted on April 25-27, 2020, reported feeling overwhelmed from trying to work at home and balance other needs of their family [12]. A review of studies on anxiety or depression during the COVID-19 pandemic reported a prevalence of $26 \%$ and $31 \%$, respectively [13]. Other studies have suggested that young people and women appear to be disproportionally affected by the COVID-19 pandemic [14-16]

Pregnant individuals may be particularly vulnerable to the negative psychological effects of public health measures related to COVID-19 [17], both because they represent the demographic most affected by disasters and because pregnancy itself entails significant life changes that require major psychosocial and emotional adjustments [18]. An early report from the current cohort [19] and other cohorts around the world [20-26] show that symptoms of depression and anxiety have increased dramatically among pregnant individuals during the COVID-19 pandemic, with greater fears surrounding social isolation and disease appearing to predict a greater risk of elevated symptoms.

Physical distancing policies implemented as a countermeasure to the spread of COVID-19 are especially concerning because social support buffers the negative effects of prenatal distress on both the mother and her offspring [27,28]. Social support and community cohesion are primary protective factors in the face of large-scale stressful events [29-31], and these factors may also apply to pandemics because countermeasures are known to increase a sense of social isolation [4].

\section{Effects of Prenatal Psychological Distress on Birth Outcomes and Child Development}

The prenatal period is a time of vulnerability for the fetus during which maternal psychological distress can have deleterious effects on fetal development. Sustained prenatal psychological distress increases the risk of prenatal and postpartum depression, prenatal infection and illness [32], miscarriage, preterm birth, and reduced birthweight [33-37]. Furthermore, children that are prenatally exposed to maternal psychological distress are more likely to have physical, behavioral, cognitive, and emotional problems than their nonexposed peers, and they are at higher risk for physical and mental health problems at a later stage [33,38-42]. Specifically, regarding disasters, a series of reports on children born to mothers exposed to the 1998 Quebec ice storm found reduced cognitive and linguistic ability [43], increased risk for obesity [44], broad changes in DNA methylation [45], and increased amygdala volume, which mediated the association between prenatal maternal stress and higher levels of externalizing behavior in these children [46]. Together, findings from disaster studies suggest that increases in psychological distress following stressful events constitute a major public health concern for physical and mental development in the generation of children prenatally exposed to the current COVID-19 pandemic.

There have also been some unexpected aspects of the COVID-19 pandemic in the context of infants. Several studies during the early pandemic $[47,48]$, although not all $[49,50]$, reported substantially increased rates of stillbirth and reduced rates of preterm birth and very low birthweight. The decrease in the rates of preterm births appears to be temporary, with rates increasing to their more usual levels as the pandemic wears on [51]. Pregnancy cohorts would serve an important role in identifying factors contributing to any changes in birth outcomes with significant potential to improve child development outcomes if the lessons learned can be applied to postpandemic obstetric care.

It is important to note that developmental outcomes of offspring prenatally exposed to maternal psychological distress are heterogeneous, and this heterogeneity strongly suggests that risk and resilience factors operate to increase or decrease the effects of prenatal exposures on maternal and offspring outcomes [52]. Emerging evidence during the current pandemic supports the notion that risk and resilience factors such as poverty, being a racial minority, psychological resources, and social support modulate the risk of contracting COVID-19 and for more severe psychological impairment during the pandemic [53-55]. Risk and resilience factors are likely to also operate in relation to health outcomes for children born during the pandemic. It is therefore essential that risk and resilience factors for child outcomes can be identified early to optimally direct efforts to enhance resilience and reduce risk [56].

The COVID-19 pandemic presents a novel and unprecedented opportunity to study stress and resilience in humans not only because of its worldwide scope but also because people around the globe are faced with similar hardships that result from public health countermeasures (eg, job loss, social isolation, and disrupted access to health care). The current situation replicates important features of well-established paradigms to study stress susceptibility and resilience in animal models [57], where animals exposed to the same stressor or hardship nevertheless show dramatically different behavioral, immunological, epigenetic, and neurobiological responses [58-60]. Stress-susceptible individuals exhibit considerable changes in behavioral and neurobiological responses, whereas stress-resilient individuals exhibit small or temporary changes in behavior and neurobiology. We propose that objective exposure to hardships caused by the pandemic and pandemic countermeasures constitute a major prenatal stressor and that outcomes in children will differ as a function of maternal susceptibility or resilience. Specifically, we postulate that, in general, greater objective exposure to prenatal hardship because of the pandemic will be associated with poorer maternal and infant outcomes. We also expect this effect will be moderated by maternal psychological response such that low or temporary increases in maternal distress (ie, stress resilience) will be associated with less severe outcomes compared to outcomes among mothers with similar exposure to objective hardship but with large increases in maternal distress (ie, stress susceptible). 
In addition to risk and resilience factors, fetal sex and timing of exposure during gestation make significant contributions to infant outcomes. Although different effects for boys and girls and across pregnancy trimesters are commonly reported, the overall findings are heterogeneous and difficult to summarize. The most pronounced sex differences have been observed for child neural or nervous system development and temperament outcomes [61]. Timing effects likely reflect vulnerabilities to environmental input at specific points in gestation (ie, sensitive periods), suggesting that it is not possible to define the specific time at which stress exposures have the greatest effects but rather that timing effects can only be specified in terms of specific outcomes [62]. For example, several large studies on stress exposure during pregnancy found the strongest associations with poor birth outcomes and behavioral disorders when exposure occurred in the second trimester [63-65], but the strongest association with affective disorders was reported when exposure occurred in the first trimester [66], and the strongest associations with neurodevelopmental disorders were reported in the third trimester [67]. However, some exposures can have opposite effects on the same outcome depending on gestational timing; for example, lower cortisol levels in early pregnancy but higher cortisol levels in later pregnancy are associated with more optimal cognitive outcomes in infants [68]. Taken together, these findings indicate the importance of including sex and exposure timing when considering the effects of the COVID-19 pandemic on offspring outcomes.

\section{Study Purpose}

The Pregnancy During the COVID-19 Pandemic (PdP) study was designed to investigate the associations among exposure to objective hardship caused by the pandemic, perceived stress and psychological distress in pregnant individuals, and developmental outcomes in their offspring. The findings of this study are intended to provide knowledge about the psychological consequences of pandemics on pregnant individuals and their offspring and point toward prevention and intervention targets.

\section{Methods}

\section{Primary Aims and Hypotheses}

\section{Aim 1}

This study aims to determine the associations among objective exposure to hardship, perceived stress, and psychological distress among pregnant individuals during the COVID-19 pandemic. We hypothesize that greater exposure to COVID-19 stressors (eg, job loss or financial strain, death of a family member) will be associated with increased symptoms of depression, anxiety, and subjective stress.

\section{Aim 2}

This study aims to determine whether prepandemic risk factors increase vulnerability to objective COVID-19 hardship. We hypothesize that drug and alcohol use prior to pregnancy, adverse childhood experiences, minority ethnicity, low educational attainment, and poverty will increase the association between objective COVID-19 hardship and maternal psychological distress.

\section{Aim 3}

This study aims to determine whether resilience factors decrease psychological distress among pregnant individuals during the COVID-19 pandemic. We hypothesize that higher partner support, better sleep quality, and more physical activity will moderate or buffer associations between objective COVID-19 hardship and maternal psychological distress.

\section{Aim 4}

This study aims to determine the associations among exposure to prenatal objective hardship, perceived stress and psychological distress, and child development outcomes. We hypothesize that objective exposure to COVID-19 hardship will be more strongly associated with poor child development among stress-susceptible individuals (who also show high levels of subjective stress and psychological distress) than among stress-resilient individuals (who have low levels of subjective stress and psychological distress despite high exposure to objective hardship).

\section{Secondary Aims (Hypothesis Generation)}

\section{Aim 5}

This study aims to determine whether gestational age at the onset of the COVID-19 pandemic is associated with infant outcomes. It is likely that each child outcome will be more strongly associated with exposure onset at some timepoints than at other timepoints during pregnancy.

\section{Aim 6}

This study aims to identify unique features of the COVID-19 pandemic that are particularly associated with increased psychological distress. We will explore potential changes in diet, physical activity, abuse, social connection, caregiving, employment, and finances.

\section{$\operatorname{Aim} 7$}

This study aims to identify unexpected aspects of the pandemic that may contribute to mental wellness or distress. We will explore potential changes in family closeness, reduction in preterm birth, and positive aspects of working from home.

\section{Study Design and Procedures}

The PdP study comprises a prospective longitudinal cohort of pregnant individuals (at enrollment) with repeated follow-ups during pregnancy and the postpartum period. Study enrollment, consent, and administration of questionnaires were conducted through Research Electronic Data Capture (REDCap) [69]. Advertisements through social media (Facebook and Instagram) directed potential participants to the study website [70] where they completed the eligibility survey and enrolled into the study. All participants signed the electronic consent form before proceeding to the first questionnaire.

An overview of the study procedure is presented in Figure 2. At enrollment, participants completed the initial survey that assessed demographic, socioeconomic, and obstetric characteristics, including age, postal code, ethnicity, household income, employment, marital status, education, country of origin, food insecurity, housing stability, history of previous 
pregnancies and births, prepregnancy health, prepregnancy height and weight, current weight, health conditions prior to and during pregnancy, medications, and other measures listed below. For the first three months following the initial survey, participants received a monthly email link to complete a follow-up survey that asked about their experiences since the previous survey. After three months, the follow-up surveys were sent every other month to reduce participant burden. Thus, participants completed a maximum of five prenatal follow-up surveys in addition to the initial survey. For each of these surveys, participants were first asked if they were still pregnant, and their answer to this question routed them either to the next prenatal survey or to the delivery survey. In the postpartum period, surveys were sent at 3, 6, and 12 months of infant age. A complete list of measures and timing of data collection are presented in Table 1.

Figure 2. Study flow diagram.

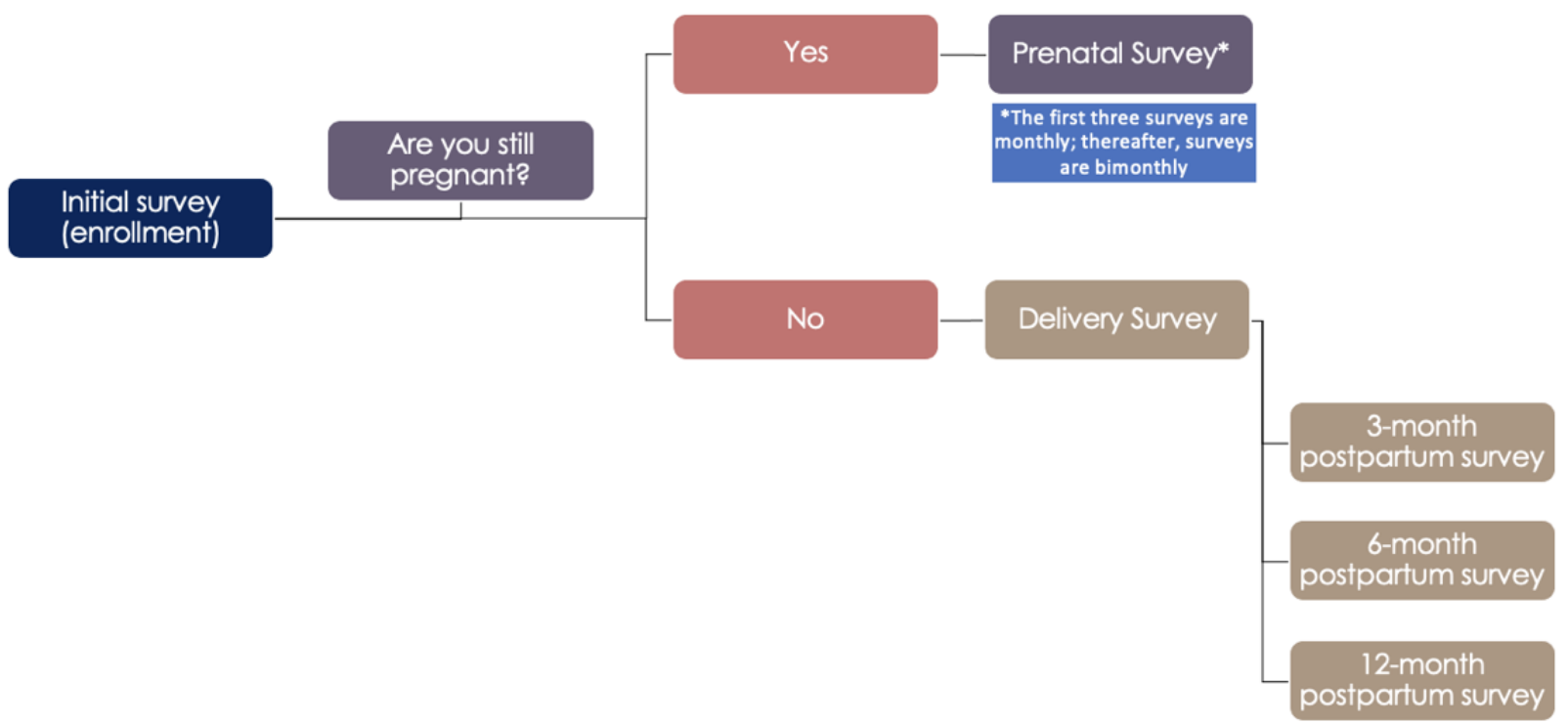


Table 1. Study measures and timepoints.

\begin{tabular}{|c|c|c|c|c|c|c|}
\hline \multirow[t]{3}{*}{ Study measures } & \multicolumn{6}{|l|}{ Timepoints } \\
\hline & \multicolumn{3}{|c|}{ Prenatal period } & \multicolumn{3}{|c|}{ Postnatal period } \\
\hline & Initial survey & $\begin{array}{l}\text { Prenatal follow- } \\
\text { up (1-5) }\end{array}$ & Delivery & 3 months & 6 months & 12 months \\
\hline
\end{tabular}

\section{General measures}

Eligibility questions and consent

Demographic information

Health behavior (eg, substance use, physical activity, and diet)

Prior, current, and changes in medical history and conditions

Pandemic Objective Hardship Scale

Perceived COVID-19 threat

Distress thermometer

Edinburgh Postpartum Depression Scale (EPDS)

Pregnancy-Related Anxiety Questionnaire

(PRAQ/PRAQ-R2)

PROMIS $^{\mathrm{a}}$ Anxiety

PROMIS Anger

PROMIS Sleep-Related Impairment

PROMIS Sleep Disturbance

Perceived Stress Scale (PSS)

Connor-Davidson Resilience Scale (CD-RISC-2)

Social isolation

Couple's Satisfaction Index (CSI)

Social Support Effectiveness Questionnaire (SSEQ)

Interpersonal Support Evaluation List (ISEL)

Intolerance of Uncertainty Scale- Short form (IUS)

Physical abuse $\left(\right.$ PRAMS $^{\mathrm{b}}$ )

Adverse Childhood Experiences $(\mathrm{ACEs})^{\mathrm{c}}$

The Everyday Discrimination Scale (EDS) ${ }^{\mathrm{c}}$

Self-compassion ${ }^{\mathrm{c}}$

Intended infant feeding

Gender identity and sexual orientation questions ${ }^{c}$

\section{Delivery measures}

Delivery type and outcome (live birth, miscarriage, and neonatal death)

Baby information and health (weight, length, sex, and $\mathrm{NICU}^{\mathrm{d}}$ stay)

Birth experience and COVID-19 restrictions during birth or NICU stay

Initial breastfeeding questions

COVID-19 impact on breastfeeding and bonding 


\begin{tabular}{|c|c|c|c|c|c|c|}
\hline \multirow[t]{3}{*}{ Study measures } & \multicolumn{6}{|l|}{ Timepoints } \\
\hline & \multicolumn{3}{|c|}{ Prenatal period } & \multicolumn{3}{|c|}{ Postnatal period } \\
\hline & Initial survey & $\begin{array}{l}\text { Prenatal follow- } \\
\text { up (1-5) }\end{array}$ & Delivery & 3 months & 6 months & 12 months \\
\hline Infant health & & & & & $\checkmark$ & $\checkmark$ \\
\hline $\begin{array}{l}\text { Ages and Stages Questionnaire, Third Edition (ASQ- } \\
\text { 3) }\end{array}$ & & & & & & $\checkmark$ \\
\hline $\begin{array}{l}\text { Ages and Stages Questionnaire: Social-Emotional, } \\
\text { Second Edition (ASQ:SE-2) }\end{array}$ & & & & & & $\checkmark$ \\
\hline Brief Infant Sleep Questionnaire (BISQ) & & & & $\checkmark$ & & $\checkmark$ \\
\hline $\begin{array}{l}\text { The Infant Behaviour Questionnaire-Revised Very } \\
\text { Short Form (IBQ-R) }\end{array}$ & & & & & $\checkmark$ & $\checkmark$ \\
\hline Crying patterns & & & & $\checkmark$ & & \\
\hline Infant feeding & & & & $\checkmark$ & $\sqrt{ }$ & $\checkmark$ \\
\hline $\begin{array}{l}\text { COVID-19 disruptions to mothers' postpartum ser- } \\
\text { vices }\end{array}$ & & & & $\checkmark$ & $\checkmark$ & $\checkmark$ \\
\hline $\begin{array}{l}\text { COVID-19 disruptions to infant appointments and } \\
\text { services }\end{array}$ & & & & $\checkmark$ & $\checkmark$ & $\checkmark$ \\
\hline
\end{tabular}

${ }^{a}$ PROMIS: Patient-Reported Outcomes Measurement Information System.

bRAMS: Pregnancy Risk Assessment Monitoring System.

${ }^{\mathrm{c}}$ These measures were only collected once.

${ }^{\mathrm{d}} \mathrm{NICU}$ : neonatal intensive care unit.

\section{Study Population}

Participants included individuals who were pregnant during the COVID-19 pandemic. Participants were considered eligible if they were $\geq 17$ years, $\leq 35$ weeks of gestation at the time of enrollment, living in Canada, and able to read and write in English or French. There were no additional exclusion criteria. The requirement of $\leq 35$ weeks of gestation at study enrollment was intended to allow us to collect multiple data points during a participant's pregnancy. However, we note that, based on their due dates, some participants were at $>35$ weeks of gestation at initial enrollment but otherwise provided legitimate data. We

plan to retain these participants for potential secondary analyses, as relevant.

Participant recruitment began on April 5, 2020, and it is currently ongoing. The recruitment goal is to obtain 9200 completed baseline surveys (see Sample Size Considerations below). To ensure broad representation, our advertising and surveys were available in both official Canadian languages (ie, French and English), and our social media ads target geographic regions and/or sociodemographic groups with less representation in the cohort (eg, rural communities in Northern Canada). Figure 3 provides a graphical summary of the geographic distribution of participants across Canada enrolled in this study to date. 
Figure 3. Geographic distribution of study participants by postal code. Figure generated using Tableau Maps.

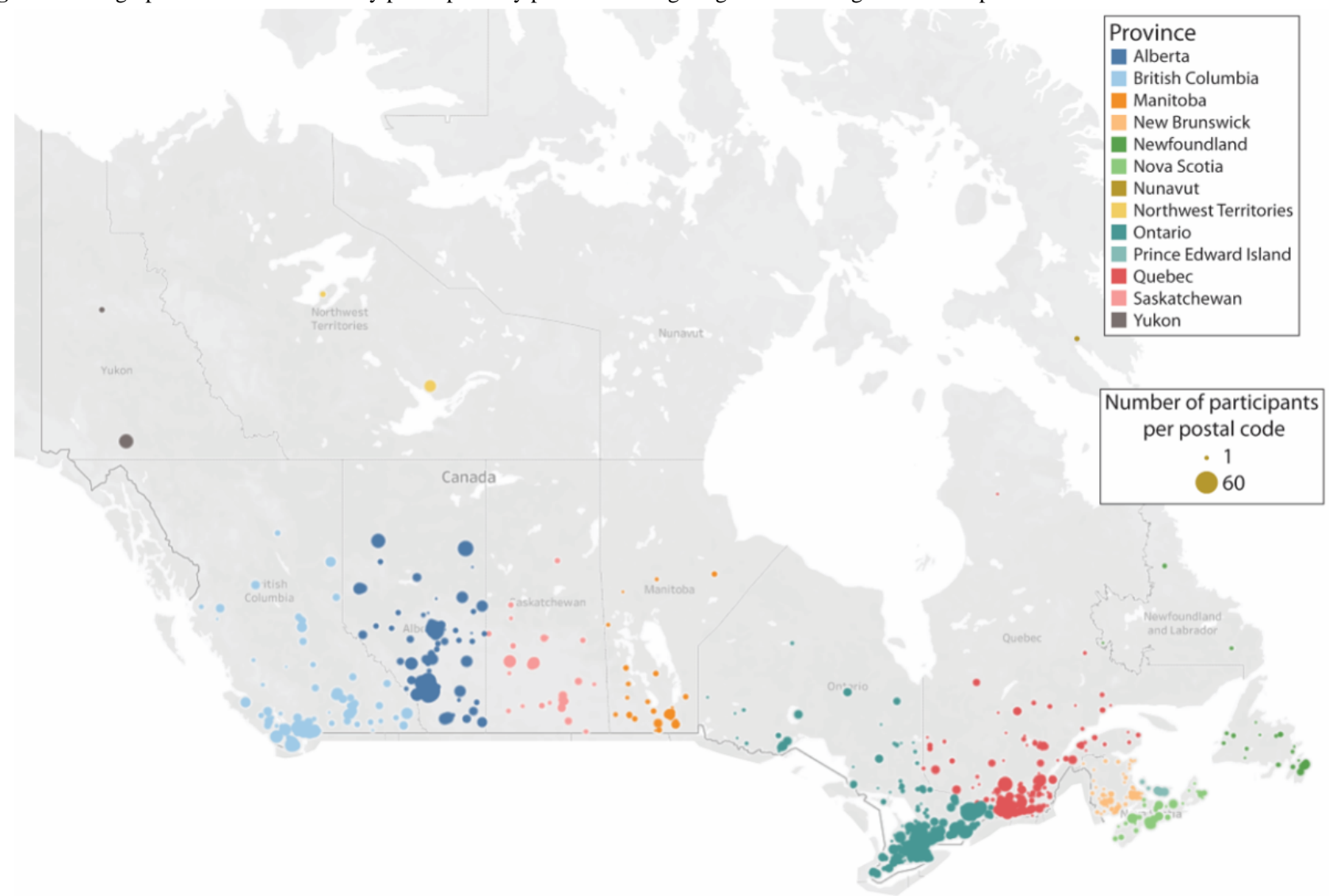

\section{Study Measures}

\section{Maternal Measures}

\section{Depression Symptoms}

Maternal depression symptoms experienced by the participants in the past week were assessed using the Edinburgh Postpartum Depression Scale (EPDS) [71], a self-report questionnaire with possible scores ranging from 0 to 30 , where higher scores indicate more severe symptoms. A cut-off score $\geq 13$ is used to identify individuals with clinically concerning depression symptoms [71]. Scores $\geq 13$ during pregnancy have a sensitivity and specificity of $100 \%$ and $87 \%$, respectively, for classifying major depression, and a positive predictive value of 33 [72]. This scale has been validated for both prenatal and postnatal assessment [73,74].

\section{Anxiety Symptoms}

General anxiety symptoms experienced by the participants in the past week were assessed using the 7-item Patient-Reported Outcomes Measurement Information System (PROMIS) Anxiety-Adult Short Form [75]. We follow the standard practice of converting raw scores to T-scores using the US general population norms; possible scores range from 36.3 to 82.7 , with a mean score of 50 (SD 10). T-scores in the range of 60-69.9 are indicative of moderately elevated anxiety symptoms, and scores $\geq 70$ are considered indicative of severely elevated anxiety symptoms [76].

Pregnancy-related anxiety symptoms (ie, worries about the health of the baby, birth, and caring for a new baby) experienced by the participants were assessed using the 10-item Pregnancy Related Anxiety Questionnaire (PRAQ) [77] in the English-language survey and the French translation of the 10-item Pregnancy Related Anxiety Questionnaire-Revised 2 (PRAQ-R2) in the French-language survey [78]. Possible scores on the PRAQ range from 10 to 40 and those on the PRAQ-R2 range from 10 to 50 . Both questionnaires have acceptable internal consistency (Cronbach $\alpha=.80-.81$ ) [78,79], and their validity is supported by extensive use in relation to both maternal and infant outcomes. There are no cut-off scores for these scales, but previous treatment studies have used a median split to define groups with higher versus lower pregnancy-related anxiety symptoms [80], with higher scores indicating more severe symptoms.

\section{Anger}

Anger experienced by the participants in the past week was assessed using the 5-item PROMIS Short Form v1.1-Anger 5a 
[75]. As with other PROMIS measures, raw scores are converted to T-scores. T-scores range from 32.9 to 82.9 ; the mean score was 50 (SD 10), with scores in the range of 60-69.9 indicative of moderately elevated anger and scores $\geq 70$ indicative of severely elevated anger [76].

\section{Distress Thermometer}

The Distress Thermometer was used to measure the overall level of subjective distress experienced by the participants in the previous week, on a visual analog scale of 0 ("Not distressed") to 10 ("Extremely distressed") [81]. A cut-off score $\geq 4$ is typically used to signify clinically concerning distress [82]. The Distress Thermometer has demonstrated good validity and temporal stability $[83,84]$.

\section{Perceived Psychological Stress}

Participants' subjective experience of psychological stress over the past month was assessed with the widely used 10-item Perceived Stress Scale (PSS) [85]. The PSS measures the degree to which participants appraise their lives as unpredictable, uncontrollable, and overloaded [86]. Scores range from 0 to 40, with higher scores indicating greater perceived stress. Reliability and validity of the PSS have been supported across multiple studies [85].

\section{Pandemic Objective Hardship Scale}

COVID-19 represents a novel exposure for which there are no previously developed measures. Nevertheless, previous work on objective measures of hardship resulting from exposure to natural disasters provided a principled and systematic framework for developing a new measure [87]. For instance, work by King and Laplante [87] has identified four major components of disaster exposures, which were adapted to the COVID-19 context: scope, loss, threat, and change. Scope refers to the duration and intensity of the hardship, with the former referring to the amount of time for which major aspects of participants' lives were disrupted and the latter focusing on the number of individuals within participants' communities who were similarly affected. Loss refers to financial, social, and physical losses experienced as a result of the pandemic. For example, the loss of employment, savings, closures of schools, and daycares represent relevant losses. Threat refers to physical and health-related consequences of exposure to the stressor. For example, being infected with SARS-CoV-2 or hospitalization of a close friend with COVID-19 represent threats to self and others. Change captures the adjustments to daily living, prenatal care, work, and social interaction caused by the COVID-19 pandemic. Relevant changes include working from home, altering a birth plan, and reductions in physical activity or diet quality. The timeframe for these items was the previous month or the previous questionnaire (ie, up to three months).

\section{Prenatal and Postnatal Care}

Changes and disruptions to prenatal and postnatal care received by the participants were assessed using a series of questions tailored to our study relating to the way that prenatal care was delivered, cancellations, ability to bring partner to appointments, and changes to birth plans. Participants are also asked to evaluate the impact of these changes on the quality of care they and their baby have received in the past three months.

\section{Perceived COVID-19 Threat}

The degree to which participants feel that COVID-19 was a threat to their health or the health of their baby at any time during the pandemic was assessed by three items developed for the study: (1) "How much do (did) you think your life is (was) in danger during the COVID-19 pandemic?" (2) "How much do (did) you think your baby's life is (was) in danger at any time during the COVID-19 pandemic?" and (3) "How much are you worried that exposure to the COVID-19 virus will harm your baby?" Responses were scored on a 100-point sliding scale, with the left anchor indicating 0 points ("Not at all"); the middle anchor, 50 points ("Somewhat"); and the right anchor, 100 points ("Very much so").

\section{Adverse Childhood Experiences}

Adverse childhood experiences (ACEs) of the participants were assessed using a 10-item measure [88] of early-life adversity (age 0-18 years) across three domains: abuse (emotional, physical, and sexual), neglect (physical and emotional), and exposure to household dysfunction (domestic violence, substance abuse, mental illness, parental separation or divorce, and incarcerated household member). The ACEs questionnaire is widely used and has demonstrated good reliability and internal consistency (Cronbach $\alpha=.81$ ) [89], as well as adequate test-retest reliability (weighted $\kappa=0.64$ ) [90]. The occurrence of individual ACEs is summed to create the ACE score with a potential range of $0-10$. Based on previous work that has examined dose-response relationships, participants were coded as having experienced $0,1,2,3$, or $\geq 4$ ACEs [88,91,92].

\section{Perceived Social Support}

Participants' perception of the quality of social support received from their romantic partner over the previous three months was assessed using the 35-item Social Support Effectiveness Questionnaire (SSEQ) [79]. Within the domains of emotional, informational, and task support, participants were asked to rate their experience over the past three months on a 5-point scale: (1) how well the quantity of support received from their partner matched the amount they wanted, (2) whether they wished the support had been different somehow, (3) how skillful their partner was at providing support, (4) how often it was difficult to solicit support, and (5) whether their partner offered support without being asked. Participants also rated the extent to which they perceived their partner's support as negatively infringing upon their self-efficacy or self-esteem. Internal consistency of the SSEQ is strong (Cronbach $\alpha=.87$ ), and it has previously been used to distinguish levels of social support in samples of pregnant individuals $[79,93,94]$. Total scores can range from 0 to 80 , with higher scores indicating more effective support.

Perceived social support was also assessed using the 12-item Interpersonal Support Evaluation List (ISEL) [95,96], to determine appraisal (eg, advice or problem solving), belongingness (eg, shared experiences), and tangible support (eg, help with daily chores) over the past three months. Here, we focus on the total score, which is the sum of the three subscales. Scores range from 12 to 48 , with a higher score indicating greater perceived support. 


\section{Social Isolation}

Feelings of social isolation were assessed using the following item: "During the COVID-19 pandemic, I have felt more alone than usual." Participants' responses were on a 100-point sliding scale, with the left anchor indicating 0 points ("Not at all"); the middle anchor, 50 points ("Somewhat"); and the right anchor, 100 points ("Very much so").

\section{Relationship Quality}

Participants' perception of partner relationship quality was assessed using the 4-item Couple Satisfaction Index (CSI-4) [97]. Scores range from 0 to 21 , with higher scores indicating higher levels of relationship satisfaction. CSI-4 scores below 13.5 suggest notable relationship dissatisfaction. Changes in relationship quality as a function of the pandemic were assessed for relationships with partner, children, and close friends and family by using items generated for the study. For each relationship type, participants were asked how the COVID-19 pandemic affected their relationship. Responses were recorded on a 100-point sliding scale, with the left anchor indicating 0 points ("It has strained our relationship"); the middle anchor, 50 points ("Not much has changed"); and the right anchor, 100 points ("It has brought us closer together"').

\section{Physical Abuse}

Experiences of physical harm in the 12 months prior to pregnancy and during the current pregnancy were assessed using two items adapted from the Pregnancy Risk Assessment Monitoring System (PRAMS) [98]. These items were queried with regard to the 12-month periods before pregnancy, since the last survey, and after giving birth.

\section{Physical Activity}

Participants reported their physical activity using a modified form of the Godin-Shephard Leisure-Time Exercise Questionnaire (GLTEQ) in a typical week over the past month [99]. Participants reported the number of days per week in which they engaged in mild (eg, light walking), moderate (eg, brisk walking), and strenuous (eg, running) exercise of more than 15 minutes. Definitions of each category of physical activity were provided. The total score was calculated per standard scoring procedure for GLTEQ, by multiplying episodes of mild exercise by 3 , moderate exercise by 5 , and strenuous exercise by 9 . Participants with scores below 14 are considered sedentary, those with scores ranging from 14 to 23 are considered moderately active, and those with scores equal to or more than 24 are considered active. An additional item was included asking participants how their level of physical activity changed because of the COVID-19 pandemic. Responses were recorded on a 5-point Likert-type scale with the following options: "Substantially decreased" (1 point), "Somewhat decreased" (2 points), "No change" (3 points), "Somewhat increased" (4 points), and "Substantially increased" (5 points).

\section{Sleep Quality}

Sleep disturbance and impairment in the past week were assessed using the 4-item PROMIS Sleep Disturbance-Short Form 4a and the 4-item PROMIS Sleep-Related Impairment-Short Form 4a [100]. As with other PROMIS measures, raw scores are converted to T-scores. T-scores ranging from 60 to 69.9 are considered moderate problems, and scores $\geq 70$ are considered severely elevated. Sleep duration (ie, hours of sleep per night) was assessed with a single item from the Pittsburgh Sleep Quality Index [101].

\section{Diet}

Changes in diet and eating patterns were assessed using a questionnaire developed for the study to determine how participants' diet during the COVID-19 pandemic differed from their prepandemic diet and the reasons for the change. Dietary changes were assessed in the following categories: fresh vegetables or fruits, dairy, meats, canned or dried foods, fast foods, take-out or home delivery, and sweets or snacks. For each category, participants responded on a 5-point Likert-type scale, with the following options: "I eat much more" (1 point), "I eat more" ( 2 points), "I eat about the same" ( 3 points), "I eat less" (4 points), and "I eat much less" (5 points). If participants reported a change in their diet (ie, did not select "I eat about the same" option), then they were asked about the reason for the change with the following response options: "Can no longer afford," "Can't go grocery shopping frequently," "Can spend more time cooking and preparing food," "Change in craving," and "Other (specify below)" (scores: Yes $=1, \mathrm{No}=0$ ). Although changes in craving were not expected as a direct result of the pandemic, they are commonly reported during pregnancy [102]; it was therefore important to disambiguate such pregnancy-related changes in diet from changes that are more directly related to the pandemic.

\section{Substance Use}

Substance use prior to (ie, in the 12 months before pregnancy) and during the current pregnancy (ie, in the past month) were assessed using a self-report measure separately for alcohol, cannabis, tobacco, and illicit drugs. Participants were asked how many days per week they consumed each substance and how many drinks or products per day they typically consumed. Participants were also asked whether they changed their use patterns in pregnancy and if they had, they were asked when they changed their use patterns.

\section{Coping and Resilience}

Participants' perceived ability to cope with stressful situations was assessed with the 2-item Connor-Davidson Resilience Scale (CD-RISC 2), which demonstrates good test-retest reliability and convergent and divergent validity [103]. Each item is rated on a 5-point Likert scale ranging from 0 ("Not true at all") to 4 ("True all the time"); total scores can range from 0 to 8 , with higher scores indicating more successful coping. We also included an open-ended question about coping: "People are responding to the pandemic in many ways. Can you tell us what things you are doing to cope with the COVID-19 pandemic?"

The 27-item Intolerance of Uncertainty Scale (IUS) was used to measure the extent to which participants believe uncertainty is stressful, upsetting, negative, unfair, and leads to the inability to take action $[104,105]$. Items are rated on a scale ranging from 1 ("Not at all characteristic of me") to 5 ("Entirely characteristic of me"). Previous research shows that the IUS has excellent internal consistency (Cronbach $\alpha=.91$ ) and good test-retest 
reliability ( $r=0.74)$, and it is highly correlated with symptoms of generalized anxiety disorder [104].

Self-compassion, a trait level form of resilience, was assessed using the 12-item short form of the Self-Compassion Scale-Short Form (SCS-SF) [106]. The SCS measures the tendency to treat oneself with kindness and understanding rather than harsh self-judgment, to recognize imperfections and suffering as part of the human experience, and to have mindful awareness and tolerance of negative thoughts and feelings. Each item is rated on a 5-point Likert scale ranging from 1 ("Almost never") to 5 ("Almost always"); total scores range from 10 to 60 , with higher scores indicating more self-compassion. The SCS has adequate internal consistency (Cronbach $\alpha=.86$ ) and strong correlation ( $r=0.97)$ with the long form [106].

\section{Discrimination}

Participants' experiences of discrimination were assessed using the 5-item Everyday Discrimination Scale [107]. This questionnaire asks about day-to-day experiences of discrimination, including being treated differently than other people and feeling threatened or harassed. Responses items ranged from 0 ("Never") to 6 ("Almost every day"). For items rated as more than "A few times a year," participants were also asked a follow-up question about what they think is the main reason for these experiences.

\section{Vaccination}

Participants were asked if they planned to receive a COVID-19 vaccine, if they had received a COVID-19 vaccine (which vaccine, if yes), and the dates of the doses (or the gestational age if they were still pregnant).

\section{Child Development Measures}

Parent report of child outcomes were assessed at 3, 6, and 12 months postpartum.

\section{Developmental Milestones}

The Ages and Stages Questionnaire, Third Edition (ASQ-3) [108] is a widely used parent-reported and norm-referenced developmental screening tool [109] that assesses delays in child development across five domains: communication, gross motor, fine motor, problem-solving, and personal adaptive skills. The ASQ-3 has been identified by the American Academy of Pediatrics as a high-quality tool for use in clinical practice to screen for delayed developmental milestones in children [110]. Sensitivity and specificity of the ASQ-3 are both $86 \%$ for distinguishing between children at risk for developmental delay and children not at risk. Parents rate each of the 30 items on a scale ranging from "Yes" (10 points), "Sometimes" (5 points), or "Not yet" (0 point) based on the infant's current ability.

\section{Socioemotional Development}

The Ages and Stages Questionnaire: Social-Emotional, Second Edition (ASQ:SE-2) [111] is a validated and widely used parent-report screening tool in 7 areas of socioemotional development: self-regulation, compliance, social communication, adaptive functioning, autonomy, affect, and interaction with people. A total score is calculated to index overall socioemotional problems. Parents rate each of the 27 items on a scale ranging from "Often or always" (0 point),
"Sometimes" (5 points), or "Rarely or never" (10 points) based on the infant's usual behavior.

\section{Temperament}

The Infant Behavior Questionnaire-Revised Very Short Form (IBQ-R) [112,113] is a 37-item parent-report measure of infant temperament. Three broad dimensions of temperament are assessed: negative emotionality, regulatory capacity/orienting, and positive affectivity/surgency. Parents report their observations of specific infant behaviors in the past week using a 7-point Likert scale ranging from "Never" to "Always." Each item also had a "Does not apply" option. Scores on each dimension can range from 1 to 7 , with higher scores reflecting stronger evidence of each dimension. The IBQ-R has strong psychometric properties and is widely used in the child development literature [114,115].

\section{Crying}

Periods of persistent infant crying (defined as half an hour or more during which the baby would not settle) in the past week were assessed using several items from the Crying Patterns Questionnaire [116]. The validity of the Crying Patterns Questionnaire, relative to a cry diary, has been supported [117].

\section{Infant's Sleep Quality}

Parents' report of their infant's sleep quality in the past two weeks was assessed using the 19-item Brief Infant Sleep Questionnaire (BISQ)-Revised Short Form [118]. In addition to a total score, three subscale scores are calculated: infant sleep (5 items), parent perception (3 items), and parent sleep-related behaviors (11 items). The measure is scored using an age-based and norm-referenced system [119]. The total score and each subscale score are scaled from 0 to 100 , with higher scores indicating better sleep quality, more positive perception of infant sleep, and parent behaviors that promote healthy and independent sleep. The BISQ is widely used, and its reliability and validity have been documented [120,121].

\section{Feeding}

Based on previously published questionnaires [122,123], we assessed onset, duration, and proportion of breastfeeding and formula feeding by using a series of maternal-report questions that conform to the World Health Organization's breastfeeding categories: exclusive breastfeeding, predominant breastfeeding, mixed feeding, and bottle feeding [124].

\section{Sample Size Considerations}

To power the study adequately for each of the hypotheses, we conducted a sample size calculation for Hypothesis 5, which will test the timing effects of prenatal exposure on child development outcomes. We choose this hypothesis because it requires the largest sample, and adequately powering this hypothesis will also adequately power the other hypotheses. We used G*Power (version 3.1) [125] to estimate the sample size required to test differences in the proportion of children not meeting developmental milestones. About $26 \%$ of children in Canada did not meet developmental milestones in one or more area of development prior to the COVID-19 pandemic [126]. To detect an increase in proportion of 0.09 not meeting developmental milestones (which is equal to the interprovincial 
variability in the proportion of children not meeting developmental milestones), assuming a power of 0.90 and $\alpha=.001$, a sample size of 2184 is required. To conduct adequately powered analyses stratified by trimester, we require a sample of 6552 with infant milestone data. Allowing for a $10 \%$ attrition due to miscarriage and stillbirth and an additional $30 \%$ attrition due to other reasons after the initial survey, we plan to recruit a total sample of 9200 .

\section{Data Analysis}

Data visualization and screening will be conducted to determine what, if any, data manipulations are required. Regression-based analysis are planned to address study hypotheses. Logistic regression will be used with categorical outcomes, and multivariable regression will be used for continuous outcomes. Longitudinal analyses will be conducted using multilevel modeling. All analyses will include covariates deemed important to control for confounding and to increase the precision of the model. Planned subgroup analyses include grouping based on established cut-off scores for measures of anxiety and depression symptoms, analyses comparing individuals with confirmed COVID-19 to those who did not have COVID-19, and analyses by child sex for child outcomes. We also plan to examine time-related factors, including timing effects related to trimester of pregnancy when the pandemic was declared and the influence of pandemic phase (ie, how stress, distress, and fear change over time) on outcomes. Missing data will be assessed to determine what treatments are required. Given the risk of attrition bias in longitudinal studies, we will use a missing data strategy that yields unbiased estimates (eg, maximum likelihood and multiple imputation).

\section{Ethical Considerations}

This study received ethics approval (REB20-0500) from the University of Calgary Conjoint Health Research Ethics Board on March 26, 2020. All participants were required to voluntarily agree to participate in this study and sign the electronic informed consent form prior to providing any data.

\section{Data Management and Availability}

Study data were collected and managed using REDCap electronic data capture tools hosted at the University of Calgary and the University of Alberta [69]. REDCap is a secure, web-based application designed to support data capture for research studies, providing (1) an intuitive interface for validated data entry, (2) audit trails for tracking data manipulation and export procedures, (3) automated export procedures for seamless data downloads to common statistical packages, and (4) procedures for importing data from external sources.

Metadata will be included in the Canadian Research Advancement through Cohort Cataloguing and Harmonization (REACH) project [127].

Data are available upon reasonable request made to the corresponding author.

\section{Results}

Participant recruitment via social media (Facebook and Instagram) began on April 5, 2020, and is ongoing. As of April 2021 , more than 11,000 individuals started the initial survey. Follow-up data collection is ongoing.

\section{Discussion}

The design and implementation of this study protocol were executed during the early phase of the pandemic with data collection starting on April 5, 2020. Because of the evolving nature of the pandemic, some of the questions specific to the pandemic required modification, and additional questions were added to reflect the emerging issues. For example, beginning in June 2020, when provincial governments began to implement phased approaches to relaunching the economy, we added questions about perceptions of these relaunch plans.

Strengths of this study include its prospective longitudinal design, implementation at an early phase of the pandemic, sample size, recruitment (and representation) from every province and territory in Canada, a measure of objective exposure to pandemic hardships, use of measures with strong psychometric properties, and measurement of many potential confounding variables. Limitations include reliance on self-report measures that are not diagnostic in nature, the potential to attract participants with higher levels of psychological distress, the potential for attrition bias because of differential loss to follow-up, and the use of a cohort design that limits causal interpretation.

This longitudinal investigation seeks to elucidate the associations between hardships caused by the COVID-19 pandemic, maternal psychological distress, child development, and risk and resilience factors that amplify or ameliorate these associations. The findings of this study are intended to provide knowledge about the psychological consequences of pandemics on pregnant individuals and point toward prevention and intervention targets.

\section{Acknowledgments}

The authors thank the participants of the Pregnancy During the COVID-19 Pandemic study for their time and effort. The authors are grateful to Martina Min for assistance with the creation of Figure 2, Tashia Christie for assistance with Table 1, and Angélica Boucher for assistance with French-language translation. This project is supported by funds from the Owerko Center at the Alberta Children's Hospital Research Institute. LTM was supported by a Career Development Award from the Canadian Child Health Clinician Scientist Program. MW is supported by an Eyes High Postdoctoral Fellowship from the University of Calgary. LR is supported by a graduate fellowship from the Alberta Children's Hospital Research Institute. ALM is supported by postdoctoral fellowships from the Social Sciences and Humanities Research Council (SSHRC) and ACHRI. 


\section{Authors' Contributions}

GFG, CL, and LTM conceptualized the study, obtained funding, and supervised data collection. GFG wrote the first draft of the manuscript. MB, MS, ALM, AD, MW, EVM, LR, and DC assisted with study design and data collection. All authors revised and approved the final manuscript.

\section{Conflicts of Interest}

None declared.

\section{References}

1. Adhanom GT. WHO Director-General's opening remarks at the media briefing on COVID-19. World Health Organization. 2020 Mar 11. URL: https://www.who.int/director-general/speeches/detail/ who-director-general-s-opening-remarks-at-the-media-briefing-on-covid-19---11-march-2020 [accessed 2021-04-22]

2. Maunder R, Lancee W, Balderson K, Bennett J, Borgundvaag B, Evans S, et al. Long-term psychological and occupational effects of providing hospital healthcare during SARS outbreak. Emerg Infect Dis 2006 Dec;12(12):1924-1932 [FREE Full text] [doi: 10.3201/eid1212.060584] [Medline: 17326946]

3. de Souza LEC, de Lima TJS, Ribeiro EM, Pessoa ALS, Figueiredo TC, Lima LBP. Mental health of parents of children with congenital Zika virus syndrome in Brazil. J Child Fam Stud 2018 Feb 1;27(4):1207-1215. [doi: 10.1007/s10826-017-0969-0]

4. Hawryluck L, Gold WL, Robinson S, Pogorski S, Galea S, Styra R. SARS control and psychological effects of quarantine, Toronto, Canada. Emerg Infect Dis 2004 Jul;10(7):1206-1212 [FREE Full text] [doi: 10.3201/eid1007.030703] [Medline: 15324539]

5. Fergusson DM, Horwood LJ, Boden JM, Mulder RT. Impact of a major disaster on the mental health of a well-studied cohort. JAMA Psychiatry 2014 Sep;71(9):1025-1031. [doi: 10.1001/jamapsychiatry.2014.652] [Medline: 25028897]

6. Adams RE, Boscarino JA. Stress and well-being in the aftermath of the World Trade Center attack: the continuing effects of a communitywide disaster. J Community Psychol 2005 Mar;33(2):175-190 [FREE Full text] [doi: 10.1002/jcop.20030] [Medline: 17106484$]$

7. Havenaar JM, Rumyantzeva GM, van den Brink W, Poelijoe NW, van den Bout J, van Engeland H, et al. Long-term mental health effects of the Chernobyl disaster: an epidemiologic survey in two former Soviet regions. Am J Psychiatry 1997 Nov;154(11):1605-1607. [doi: 10.1176/ajp.154.11.1605] [Medline: 9356574]

8. Goldmann E, Galea S. Mental health consequences of disasters. Annu Rev Public Health 2014;35:169-183. [doi: 10.1146/annurev-publhealth-032013-182435] [Medline: 24159920]

9. McFarlane AC, Williams R. Mental health services required after disasters: learning from the lasting effects of disasters. Depress Res Treat 2012;2012:970194 [FREE Full text] [doi: 10.1155/2012/970194] [Medline: 22811897]

10. Knight M. Characteristics and outcomes of pregnant women hospitalised with confirmed SARS-CoV-2 infection in the UK: a national cohort study using the UK Obstetric Surveillance System (UKOSS). medRxiv. Preprint posted online on May 12, 2020. [doi: 10.1101/2020.05.08.20089268]

11. CEMPPR Lab (Collaboration on Emergency Management, Policy, and Preparedness Research). URL: https://www. cemppr.org/research/covid-19-in-canada [accessed 2021-04-16]

12. NA. Harris poll COVID-19 Survey wave 9. Harris Insight \& Analytics 2020:2020.

13. Tomfohr-Madsen LM, Racine N, Giesbrecht GF, Lebel C, Madigan S. Depression and anxiety in pregnancy during COVID-19: A rapid review and meta-analysis. Psychiatry Res 2021 Apr 01;300:113912. [doi:

10.1016/j.psychres.2021.113912] [Medline: 33836471]

14. Huang Y, Zhao N. Corrigendum to Generalized anxiety disorder, depressive symptoms and sleep quality during COVID-19 outbreak in China: a web-based cross-sectional survey [Psychiatry Research, 288 (2020) 112954]. Psychiatry Res 2021 Apr 07:113803 [FREE Full text] [doi: 10.1016/j.psychres.2021.113803] [Medline: 33838927]

15. Qiu J, Shen B, Zhao M, Wang Z, Xie B, Xu Y. A nationwide survey of psychological distress among Chinese people in the COVID-19 epidemic: implications and policy recommendations. Gen Psychiatr 2020;33(2):e100213 [FREE Full text] [doi: 10.1136/gpsych-2020-100213] [Medline: 32215365]

16. Hamel L, Salanicoff A. Is there a widening gender gap in coronavirus stress? Kaiser Family Foundation. 2020 Apr 6. URL: https://www.kff.org/policy-watch/is-there-widening-gender-gap-in-coronavirus-stress/ [accessed 2021-04-16]

17. Caparros-Gonzalez RA, Alderdice F. The COVID-19 pandemic and perinatal mental health. J Reprod Infant Psychol 2020 Jul;38(3):223-225. [doi: 10.1080/02646838.2020.1786910] [Medline: 32615801]

18. Dunkel Schetter C. Psychological science on pregnancy: stress processes, biopsychosocial models, and emerging research issues. Annu Rev Psychol 2011;62:531-558. [doi: 10.1146/annurev.psych.031809.130727] [Medline: 21126184]

19. Lebel C, MacKinnon A, Bagshawe M, Tomfohr-Madsen L, Giesbrecht G. Elevated depression and anxiety symptoms among pregnant individuals during the COVID-19 pandemic. J Affect Disord 2020 Dec 01;277:5-13 [FREE Full text] [doi: 10.1016/j.jad.2020.07.126] [Medline: $\underline{32777604]}$ 
20. Ceulemans M, Hompes T, Foulon V. Mental health status of pregnant and breastfeeding women during the COVID-19 pandemic: A call for action. Int J Gynaecol Obstet 2020 Oct;151(1):146-147. [doi: 10.1002/ijgo.13295] [Medline: 32620037]

21. Wu Y, Zhang C, Liu H, Duan C, Li C, Fan J, et al. Perinatal depressive and anxiety symptoms of pregnant women during the coronavirus disease 2019 outbreak in China. Am J Obstet Gynecol 2020 Aug;223(2):240.e1-240.e9 [FREE Full text] [doi: 10.1016/j.ajog.2020.05.009] [Medline: 32437665]

22. Davenport MH, Meyer S, Meah VL, Strynadka MC, Khurana R. Moms are not OK: COVID-19 and maternal mental health. Front Glob Womens Health 2020 Jun 19;1. [doi: 10.3389/fgwh.2020.00001]

23. Durankuş F, Aksu E. Effects of the COVID-19 pandemic on anxiety and depressive symptoms in pregnant women: a preliminary study. J Matern Fetal Neonatal Med 2020 May 18:1-7. [doi: 10.1080/14767058.2020.1763946] [Medline: 32419558]

24. Stampini V. A survey among Italian pregnant women and new-mothers during the COVID-19 pandemic lockdown. Research Square. Preprint posted online on August 10, 2020. [doi: 10.21203/rs.3.rs-50602/v1]

25. Taubman-Ben-Ari O, Chasson M, Abu Sharkia S, Weiss E. Distress and anxiety associated with COVID-19 among Jewish and Arab pregnant women in Israel. J Reprod Infant Psychol 2020 Jul;38(3):340-348. [doi: 10.1080/02646838.2020.1786037] [Medline: $\underline{32573258]}$

26. Patabendige M, Gamage MM, Weerasinghe M, Jayawardane A. Psychological impact of the COVID-19 pandemic among pregnant women in Sri Lanka. Int J Gynaecol Obstet 2020 Oct;151(1):150-153. [doi: 10.1002/ijgo.13335] [Medline: $\underline{\text { 32731307] }}$

27. Reid KM, Taylor MG. Social support, stress, and maternal postpartum depression: A comparison of supportive relationships. Soc Sci Res 2015 Nov;54:246-262. [doi: 10.1016/j.ssresearch.2015.08.009] [Medline: 26463547]

28. Thomas JC, Letourneau N, Campbell TS, Giesbrecht GF. Social buffering of the maternal and infant HPA axes: Mediation and moderation in the intergenerational transmission of adverse childhood experiences. Dev Psychopathol 2018 Aug 02;30(3):921-939. [doi: 10.1017/s0954579418000512]

29. Fritz J, de Graaff AM, Caisley H, van Harmelen A, Wilkinson PO. A Systematic Review of Amenable Resilience Factors That Moderate and/or Mediate the Relationship Between Childhood Adversity and Mental Health in Young People. Front Psychiatry 2018;9:230. [doi: 10.3389/fpsyt.2018.00230] [Medline: 29971021]

30. Bonanno GA, Gupta S. Resliience after disaster. In: Neria Y, Galea S, Norrise FH, editors. Mental Health and Disasters. New York: Cambridge University Press; 2009:145-160.

31. Townshend I, Awosoga O, Kulig J, Fan H. Social cohesion and resilience across communities that have experienced a disaster. Nat Hazards 2014 Nov 16;76(2):913-938. [doi: 10.1007/s11069-014-1526-4]

32. Coussons-Read ME. Effects of prenatal stress on pregnancy and human development: mechanisms and pathways. Obstet Med 2013 Jun 01;6(2):52-57. [doi: 10.1177/1753495x12473751]

33. Stein A, Pearson RM, Goodman SH, Rapa E, Rahman A, McCallum M, et al. Effects of perinatal mental disorders on the fetus and child. The Lancet 2014 Nov;384(9956):1800-1819. [doi: 10.1016/s0140-6736(14)61277-0]

34. Rondó PHC, Ferreira RF, Nogueira F, Ribeiro MCN, Lobert H, Artes R. Maternal psychological stress and distress as predictors of low birth weight, prematurity and intrauterine growth retardation. Eur J Clin Nutr 2003 Feb;57(2):266-272. [doi: 10.1038/sj.ejcn.1601526] [Medline: 12571658]

35. Accortt EE, Cheadle ACD, Dunkel Schetter C. Prenatal depression and adverse birth outcomes: an updated systematic review. Matern Child Health J 2015 Jun;19(6):1306-1337 [FREE Full text] [doi: 10.1007/s10995-014-1637-2] [Medline: 25452215]

36. Grigoriadis S, Graves L, Peer M, Mamisashvili L, Tomlinson G, Vigod SN, et al. Maternal Anxiety During Pregnancy and the Association With Adverse Perinatal Outcomes. J. Clin. Psychiatry 2018 Sep 4;79(5):17r12011. [doi: 10.4088/jcp.17r12011]

37. Qu F, Wu Y, Zhu Y, Barry J, Ding T, Baio G, et al. The association between psychological stress and miscarriage: A systematic review and meta-analysis. Sci Rep 2017 May 11;7(1):1731 [FREE Full text] [doi: 10.1038/s41598-017-01792-3] [Medline: 28496110]

38. Glover V. Maternal depression, anxiety and stress during pregnancy and child outcome; what needs to be done. Best Pract Res Clin Obstet Gynaecol 2014 Jan;28(1):25-35. [doi: 10.1016/j.bpobgyn.2013.08.017] [Medline: 24090740]

39. Van den Bergh BRH, Dahnke R, Mennes M. Prenatal stress and the developing brain: Risks for neurodevelopmental disorders. Dev Psychopathol 2018 Aug 02;30(3):743-762. [doi: 10.1017/s0954579418000342]

40. Van den Bergh BR, van den Heuvel MI, Lahti M, Braeken M, de Rooij SR, Entringer S, et al. Prenatal developmental origins of behavior and mental health: The influence of maternal stress in pregnancy. Neurosci Biobehav Rev 2020 Oct;117:26-64. [doi: 10.1016/j.neubiorev.2017.07.003] [Medline: 28757456]

41. MacKinnon N, Kingsbury M, Mahedy L, Evans J, Colman I. The association between prenatal stress and externalizing symptoms in childhood: Evidence from the Avon longitudinal study of parents and children. Biol Psychiatry 2018 Jan 15;83(2):100-108. [doi: 10.1016/j.biopsych.2017.07.010] [Medline: 28893381]

42. Entringer S, Buss C, Wadhwa PD. Prenatal stress, development, health and disease risk: A psychobiological perspective-2015 Curt Richter Award Paper. Psychoneuroendocrinology 2015 Dec;62:366-375 [FREE Full text] [doi:

10.1016/j.psyneuen.2015.08.019] [Medline: 26372770] 
43. Laplante DP, Brunet A, Schmitz N, Ciampi A, King S. Project Ice Storm: prenatal maternal stress affects cognitive and linguistic functioning in 5 1/2-year-old children. Journal of the American Academy of Child \& Adolescent Psychiatry 2008 Sep;47(9):1063-1072. [doi: 10.1097/chi.0b013e31817eec80]

44. Dancause KN, Laplante DP, Fraser S, Brunet A, Ciampi A, Schmitz N, et al. Prenatal exposure to a natural disaster increases risk for obesity in 51/2-year-old children. Pediatr Res 2012 Jan;71(1):126-131. [doi: 10.1038/pr.2011.18] [Medline: 22289861]

45. Cao-Lei L, Massart R, Suderman MJ, Machnes Z, Elgbeili G, Laplante DP, et al. DNA methylation signatures triggered by prenatal maternal stress exposure to a natural disaster: Project Ice Storm. PLoS One 2014;9(9):e107653 [FREE Full text] [doi: 10.1371/journal.pone.0107653] [Medline: 25238154]

46. Jones SL, Dufoix R, Laplante DP, Elgbeili G, Patel R, Chakravarty MM, et al. Larger amygdala volume mediates the association between prenatal maternal stress and higher levels of externalizing behaviors: sex specific effects in project ice storm. Front Hum Neurosci 2019;13:144. [doi: 10.3389/fnhum.2019.00144] [Medline: $\underline{31156408]}$

47. Philip R. Reduction in preterm births during the COVID-19 lockdown in Ireland: a natural experiment allowing analysis of data from the prior two decades. medRxiv. Preprint posted online on June 05, 2020. [doi: 10.1101/2020.06.03.20121442]

48. Hedermann G. Changes in premature birth rates during the Danish nationwide COVID-19 lockdown: a nationwide register-based prevalence proportion study. medRxiv. Preprint posted online on May 23, 2020. [doi: $10.1101 / 2020.05 .22 .20109793]$

49. Khalil A, von Dadelszen P, Draycott T, Ugwumadu A, O'Brien P, Magee L. Change in the incidence of stillbirth and preterm delivery during the COVID-19 pandemic. JAMA 2020 Jul 10;324(7):705-706 [FREE Full text] [doi: 10.1001/jama.2020.12746] [Medline: 32648892]

50. KC A, Gurung R, Kinney MV, Sunny AK, Moinuddin M, Basnet O, et al. Effect of the COVID-19 pandemic response on intrapartum care, stillbirth, and neonatal mortality outcomes in Nepal: a prospective observational study. The Lancet Global Health 2020 Oct;8(10):e1273-e1281. [doi: 10.1016/s2214-109x(20)30345-4]

51. Fieber P. Calgary doctor says 'dramatic' $40 \%$ drop in preterm births during lockdown could be global trend. CBC News. 2020 Jul 27. URL: https://www.cbc.ca/news/canada/calgary/ fewer-premature-preterm-babies-born-during-pandemic-calgary-around-the-world-1.5665089 [accessed 2021-04-16]

52. García-León MA, Caparrós-González RA, Romero-González B, González-Perez R, Peralta-Ramírez I. Resilience as a protective factor in pregnancy and puerperium: Its relationship with the psychological state, and with Hair Cortisol Concentrations. Midwifery 2019 Aug;75:138-145. [doi: 10.1016/j.midw.2019.05.006] [Medline: 31102974]

53. Havnen A, Anyan F, Hjemdal O, Solem S, Gurigard Riksfjord M, Hagen K. Resilience moderates negative outcome from stress during the COVID-19 pandemic: A moderated-mediation approach. Int J Environ Res Public Health 2020 Sep 04;17(18):6461 [FREE Full text] [doi: 10.3390/ijerph17186461] [Medline: 32899835]

54. Wilder JM. The disproportionate impact of COVID-19 on racial and ethnic minorities in the United States. Clin Infect Dis 2021 Feb 16;72(4):707-709 [FREE Full text] [doi: 10.1093/cid/ciaa959] [Medline: 32648581]

55. Ambrose AJH. Inequities During COVID-19. Pediatrics 2020 Aug;146(2):e20201501. [doi: 10.1542/peds.2020-1501] [Medline: $\underline{32747590]}$

56. Vinkers CH, van Amelsvoort T, Bisson JI, Branchi I, Cryan JF, Domschke K, et al. Stress resilience during the coronavirus pandemic. Eur Neuropsychopharmacol 2020 Jun;35:12-16 [FREE Full text] [doi: 10.1016/j.euroneuro.2020.05.003] [Medline: $\underline{\text { 32446705] }}$

57. Golden SA, Covington HE, Berton O, Russo SJ. A standardized protocol for repeated social defeat stress in mice. Nat Protoc 2011 Jul 21;6(8):1183-1191 [FREE Full text] [doi: 10.1038/nprot.2011.361] [Medline: 21799487]

58. Gururajan A, van de Wouw M, Boehme M, Becker T, O'Connor R, Bastiaanssen TF, et al. Resilience to chronic stress is associated with specific neurobiological, neuroendocrine and immune responses. Brain Behav Immun 2019 Aug;80:583-594. [doi: 10.1016/j.bbi.2019.05.004] [Medline: 31059807]

59. Krishnan V, Han M, Graham DL, Berton O, Renthal W, Russo SJ, et al. Molecular adaptations underlying susceptibility and resistance to social defeat in brain reward regions. Cell 2007 Oct 19;131(2):391-404 [FREE Full text] [doi: 10.1016/j.cell.2007.09.018] [Medline: 17956738]

60. Taliaz D, Loya A, Gersner R, Haramati S, Chen A, Zangen A. Resilience to chronic stress is mediated by hippocampal brain-derived neurotrophic factor. Journal of Neuroscience 2011 Mar 23;31(12):4475-4483. [doi: 10.1523/jneurosci.5725-10.2011]

61. Sutherland S, Brunwasser SM. Sex differences in vulnerability to prenatal stress: a review of the recent literature. Curr Psychiatry Rep 2018 Sep 18;20(11):102 [FREE Full text] [doi: 10.1007/s11920-018-0961-4] [Medline: 30229468]

62. King S, Dancause K, Turcotte-Tremblay A, Veru F, Laplante DP. Using natural disasters to study the effects of prenatal maternal stress on child health and development. Birth Defects Res C Embryo Today 2012 Dec;96(4):273-288. [doi: 10.1002/bdrc.21026] [Medline: 24203917]

63. Class QA, Lichtenstein P, Långström N, D'Onofrio BM. Timing of prenatal maternal exposure to severe life events and adverse pregnancy outcomes: a population study of 2.6 million pregnancies. Psychosom Med 2011 Apr;73(3):234-241 [FREE Full text] [doi: 10.1097/PSY.0b013e31820a62ce] [Medline: 21321257] 
64. Khashan AS, Everard C, McCowan LME, Dekker G, Moss-Morris R, Baker PN, et al. Second-trimester maternal distress increases the risk of small for gestational age. Psychol. Med 2014 Feb 27;44(13):2799-2810. [doi: $10.1017 / \mathrm{s} 0033291714000300]$

65. Bendiksen B, Aase H, Diep LM, Svensson E, Friis S, Zeiner P. The associations between pre-and postnatal maternal symptoms of distress and preschooler?s symptoms of ADHD, oppositional defiant disorder, conduct disorder, and anxiety. J Atten Disord 2020 May 07;24(7):1057-1069. [doi: 10.1177/1087054715616185] [Medline: 26647350]

66. Kleinhaus K, Harlap S, Perrin M, Manor O, Margalit-Calderon R, Opler M, et al. Prenatal stress and affective disorders in a population birth cohort. Bipolar Disord 2013 Feb;15(1):92-99. [doi: 10.1111/bdi.12015] [Medline: 23339677]

67. Manzari N, Matvienko-Sikar K, Baldoni F, O'Keeffe GW, Khashan AS. Prenatal maternal stress and risk of neurodevelopmental disorders in the offspring: a systematic review and meta-analysis. Soc Psychiatry Psychiatr Epidemiol 2019 Nov;54(11):1299-1309. [doi: 10.1007/s00127-019-01745-3] [Medline: 31324962]

68. Davis E, Sandman CA. The timing of prenatal exposure to maternal cortisol and psychosocial stress is associated with human infant cognitive development. Child Dev 2010;81(1):131-148 [FREE Full text] [doi: 10.1111/j.1467-8624.2009.01385.x] [Medline: $\underline{20331658]}$

69. Harris PA, Taylor R, Thielke R, Payne J, Gonzalez N, Conde JG. Research electronic data capture (REDCap)--a metadata-driven methodology and workflow process for providing translational research informatics support. J Biomed Inform 2009 Apr;42(2):377-381 [FREE Full text] [doi: 10.1016/j.jbi.2008.08.010] [Medline: 18929686]

70. Pregnancy During the Pandemic. URL: https://www.pregnancyduringthepandemic.com/ [accessed 2021-04-16]

71. Cox JL, Holden JM, Sagovsky R. Detection of postnatal depression. Development of the 10-item Edinburgh Postnatal Depression Scale. Br J Psychiatry 1987 Jun;150:782-786. [doi: 10.1192/bjp.150.6.782] [Medline: 3651732]

72. Murray D, Cox JL. Screening for depression during pregnancy with the Edinburgh Depression Scale (EPDS). Journal of Reproductive and Infant Psychology 1990 Apr;8(2):99-107. [doi: 10.1080/02646839008403615]

73. Bergink V, Kooistra L, Lambregtse-van den Berg MP, Wijnen H, Bunevicius R, van Baar A, et al. Validation of the Edinburgh Depression Scale during pregnancy. J Psychosom Res 2011 Apr;70(4):385-389. [doi: 10.1016/j.jpsychores.2010.07.008] [Medline: 21414460]

74. Kozinszky Z, Dudas RB. Validation studies of the Edinburgh Postnatal Depression Scale for the antenatal period. J Affect Disord 2015 May 01;176:95-105. [doi: 10.1016/j.jad.2015.01.044] [Medline: 25704562]

75. Pilkonis PA, Choi SW, Reise SP, Stover AM, Riley WT, Cella D, PROMIS Cooperative Group. Item banks for measuring emotional distress from the Patient-Reported Outcomes Measurement Information System (PROMIS®): depression, anxiety, and anger. Assessment 2011 Sep;18(3):263-283 [FREE Full text] [doi: 10.1177/1073191111411667] [Medline: 21697139]

76. Cella D, Riley W, Stone A, Rothrock N, Reeve B, Yount S, PROMIS Cooperative Group. The Patient-Reported Outcomes Measurement Information System (PROMIS) developed and tested its first wave of adult self-reported health outcome item banks: 2005-2008. J Clin Epidemiol 2010 Nov;63(11):1179-1194 [FREE Full text] [doi: 10.1016/j.jclinepi.2010.04.011] [Medline: 20685078]

77. Rini CK, Dunkel-Schetter C, Wadhwa PD, Sandman CA. Psychological adaptation and birth outcomes: The role of personal resources, stress, and sociocultural context in pregnancy. Health Psychology 1999;18(4):333-345. [doi: 10.1037/0278-6133.18.4.333]

78. Reymond C, Derguy C, Wendland J, Loyal D. Validation française d'une échelle d'anxiété spécifique à la grossesse (PRAQ-R2). Pratiques Psychologiques 2020 Jul;26(3):231-240. [doi: 10.1016/j.prps.2018.11.008]

79. RINI C, SCHETTER CD, HOBEL CJ, GLYNN LM, SANDMAN CA. Effective social support: Antecedents and consequences of partner support during pregnancy. Personal Relationships 2006 Jun;13(2):207-229. [doi: 10.1111/j.1475-6811.2006.00114.x ]

80. Urizar GG, Yim IS, Rodriguez A, Schetter CD. The SMART Moms Program: A Randomized Trial of the Impact of Stress Management on Perceived Stress and Cortisol in Low-Income Pregnant Women. Psychoneuroendocrinology 2019 Jun;104:174-184. [doi: 10.1016/j.psyneuen.2019.02.022] [Medline: 30852278]

81. Roth AJ, Kornblith AB, Batel-Copel L, Peabody E, Scher HI, Holland JC. Rapid screening for psychologic distress in men with prostate carcinoma. Cancer 1998 May 15;82(10):1904-1908. [doi: 10.1002/(sici)1097-0142(19980515)82:10<1904::aid-cncr13>3.0.c0;2-x]

82. Ma X, Zhang J, Zhong W, Shu C, Wang F, Wen J, et al. The diagnostic role of a short screening tool--the distress thermometer: a meta-analysis. Support Care Cancer 2014 Jul;22(7):1741-1755. [doi: 10.1007/s00520-014-2143-1] [Medline: 24510195]

83. Donovan KA, Grassi L, McGinty HL, Jacobsen PB. Validation of the distress thermometer worldwide: state of the science. Psychooncology 2014 Mar;23(3):241-250. [doi: 10.1002/pon.3430] [Medline: 25160838]

84. Leclair T, Carret A, Samson Y, Sultan S. Stability and repeatability of the Distress Thermometer (DT) and the Edmonton Symptom Assessment System-Revised (ESAS-r) with parents of childhood cancer survivors. PLoS One 2016 Jul 25;11(7):e0159773 [FREE Full text] [doi: 10.1371/journal.pone.0159773] [Medline: 27454432]

85. Cohen S, Kamarck T, Mermelstein R. A global measure of perceived stress. J Health Soc Behav 1983 Dec;24(4):385. [doi: $10.2307 / 2136404]$ 
86. Cohen S. Contrasting the Hassles Scale and the Perceived Stress Scale: Who's really measuring appraised stress? American Psychologist 1986;41(6):716-718. [doi: 10.1037/0003-066x.41.6.716]

87. King S, Laplante DP. Using natural disasters to study prenatal maternal stress in humans. Adv Neurobiol 2015;10:285-313. [doi: 10.1007/978-1-4939-1372-5_14] [Medline: 25287546]

88. Felitti VJ, Anda RF, Nordenberg D, Williamson DF, Spitz AM, Edwards V, et al. Relationship of childhood abuse and household dysfunction to many of the leading causes of death in adults: The Adverse Childhood Experiences (ACE) Study. Am J Prev Med 1998 May;14(4):245-258. [doi: 10.1016/s0749-3797(98)00017-8]

89. Bruskas D, Tessin DH. Adverse childhood experiences and psychosocial well-being of women who were in foster care as children. Perm J 2013;17(3):e131-e141 [FREE Full text] [doi: 10.7812/TPP/12-121] [Medline: 24355905]

90. Dube SR, Williamson DF, Thompson T, Felitti VJ, Anda RF. Assessing the reliability of retrospective reports of adverse childhood experiences among adult HMO members attending a primary care clinic. Child Abuse Negl 2004 Jul;28(7):729-737. [doi: 10.1016/j.chiabu.2003.08.009] [Medline: 15261468]

91. Anda RF, Felitti VJ, Bremner JD, Walker JD, Whitfield C, Perry BD, et al. The enduring effects of abuse and related adverse experiences in childhood. A convergence of evidence from neurobiology and epidemiology. Eur Arch Psychiatry Clin Neurosci 2006 Apr;256(3):174-186 [FREE Full text] [doi: 10.1007/s00406-005-0624-4] [Medline: 16311898]

92. Merrick MT, Ports KA, Ford DC, Afifi TO, Gershoff ET, Grogan-Kaylor A. Unpacking the impact of adverse childhood experiences on adult mental health. Child Abuse Negl 2017 Jul;69:10-19 [FREE Full text] [doi: 10.1016/j.chiabu.2017.03.016] [Medline: 28419887]

93. Stapleton LRT, Schetter CD, Westling E, Rini C, Glynn LM, Hobel CJ, et al. Perceived partner support in pregnancy predicts lower maternal and infant distress. J Fam Psychol 2012 Jun;26(3):453-463 [FREE Full text] [doi: 10.1037/a0028332] [Medline: 22662772]

94. Giesbrecht G, Poole JC, Letourneau N, Campbell T, Kaplan BJ, APrON Study Team. The buffering effect of social support on hypothalamic-pituitary-adrenal axis function during pregnancy. Psychosom Med 2013;75(9):856-862. [doi: 10.1097/PSY.0000000000000004] [Medline: 24163383]

95. Cohen S, Hoberman HM. Positive events and social supports as buffers of life change stress. J Appl Social Pyschol 1983 Apr;13(2):99-125. [doi: 10.1111/j.1559-1816.1983.tb02325.x]

96. Cohen S, Mermelstein R, Kamarck T, Hoberman H. Measuring the functional components of social support, in Social support: Theory, research and applications. Springer 1985:73-94. [doi: 10.1007/978-94-009-5115-0_5]

97. Funk JL, Rogge RD. Testing the ruler with item response theory: increasing precision of measurement for relationship satisfaction with the Couples Satisfaction Index. J Fam Psychol 2007 Dec;21(4):572-583. [doi: 10.1037/0893-3200.21.4.572] [Medline: 18179329]

98. PRAMS Questionnaires. Centers for Disease Control and Prevention. URL: https://www.cdc.gov/prams/questionnaire.htm [accessed 2021-04-16]

99. Godin G. The Godin-Shephard leisure-time physical activity questionnaire. Health \& Fitness Journal of Canada 2011;4(1):18-22.

100. Yu L, Buysse DJ, Germain A, Moul DE, Stover A, Dodds NE, et al. Development of short forms from the PROMISTM sleep disturbance and Sleep-Related Impairment item banks. Behav Sleep Med 2011 Dec 28;10(1):6-24 [FREE Full text] [doi: 10.1080/15402002.2012.636266] [Medline: 22250775]

101. Buysse DJ, Reynolds CF, Monk TH, Berman SR, Kupfer DJ. The Pittsburgh sleep quality index: A new instrument for psychiatric practice and research. Psychiatry Research 1989 May;28(2):193-213. [doi: 10.1016/0165-1781(89)90047-4]

102. Orloff NC, Hormes JM. Pickles and ice cream! Food cravings in pregnancy: hypotheses, preliminary evidence, and directions for future research. Front Psychol 2014;5:1076 [FREE Full text] [doi: 10.3389/fpsyg. 2014.01076] [Medline: 25295023]

103. Vaishnavi S, Connor K, Davidson JR. An abbreviated version of the Connor-Davidson Resilience Scale (CD-RISC), the CD-RISC2: psychometric properties and applications in psychopharmacological trials. Psychiatry Res 2007 Aug 30;152(2-3):293-297 [FREE Full text] [doi: 10.1016/j.psychres.2007.01.006] [Medline: 17459488]

104. Buhr K, Dugas M. The intolerance of uncertainty scale: psychometric properties of the English version. Behaviour Research and Therapy 2002 Aug;40(8):931-945. [doi: 10.1016/s0005-7967(01)00092-4]

105. Buhr K, Dugas MJ. Investigating the construct validity of intolerance of uncertainty and its unique relationship with worry. J Anxiety Disord 2006 Jan;20(2):222-236. [doi: 10.1016/j.janxdis.2004.12.004] [Medline: 16464706]

106. Raes F, Pommier E, Neff KD, Van Gucht D. Construction and factorial validation of a short form of the Self-Compassion Scale. Clin Psychol Psychother 2011;18(3):250-255. [doi: 10.1002/cpp.702] [Medline: 21584907]

107. Williams DR, Yan Y, Jackson JS, Anderson NB. Racial differences in physical and mental health: Socio-economic status, stress and discrimination. J Health Psychol 1997 Jul 01;2(3):335-351. [doi: 10.1177/135910539700200305] [Medline: 22013026]

108. Squires J, Bricker D. Ages \& Stages Questionnaire, Third Edition (ASQ-3): A parent-completed child monitoring system. Baltimore: Paul H. Brooks Publishing Co., Inc; 2009.

109. Rothstein A, Miskovic A, Nitsch K. Brief review of psychometric properties and clinical utility of the Ages and Stages Questionnaires, Third Edition for evaluating pediatric development. Arch Phys Med Rehabil 2017 Apr;98(4):809-810. [doi: 10.1016/j.apmr.2016.11.001] 
110. NA. Developmental surveillance and screening of infants and young children. Pediatrics 2001 Jul;108(1):192-196. [doi: 10.1542/peds.108.1.192] [Medline: 11433077$]$

111. Squires J, Bricker D, Twombly E. Ages \& stages questionnaires: Social-emotional. Vol. 2. Baltimore, MD: Paul H. Brookes Publishing Company; 2002.

112. Gartstein MA, Rothbart MK. Studying infant temperament via the Revised Infant Behavior Questionnaire. Infant Behavior and Development 2003 Feb;26(1):64-86. [doi: 10.1016/s0163-6383(02)00169-8]

113. Putnam S, Helbig AL, Gartstein MA, Rothbart MK, Leerkes E. Development and assessment of short and very short forms of the infant behavior questionnaire-revised. J Pers Assess 2014;96(4):445-458. [doi: 10.1080/00223891.2013.841171] [Medline: 24206185]

114. Gartstein MA, Slobodskaya HR, Putnam SP, Kinsht IA. A cross-cultural study of infant temperament: Predicting preschool effortful control in the United States of America and Russia. European Journal of Developmental Psychology 2009 Apr 08;6(3):337-364. [doi: 10.1080/17405620701203846]

115. Pauli-Pott U, Mertesacker B, Bade U, Haverkock A, Beckmann D. Parental perceptions and infant temperament development. Infant Behavior and Development 2003 Feb;26(1):27-48. [doi: 10.1016/s0163-6383(02)00167-4]

116. St James-Roberts I, Halil T. Infant crying patterns in the first year: normal community and clinical findings. J Child Psychol Psychiatry 1991 Sep;32(6):951-968. [doi: 10.1111/j.1469-7610.1991.tb01922.x] [Medline: 1744198]

117. Wolke D, Meyer R, Gray P. Validity of the crying pattern questionnaire in a sample of excessively crying babies. J Reprod Infant Psychol 1994 Apr;12(2):105-114. [doi: 10.1080/02646839408408873]

118. Mindell JA, Gould RA, Tikotzy L, Leichman ES, Walters RM. Norm-referenced scoring system for the Brief Infant Sleep Questionnaire - Revised (BISQ-R). Sleep Med 2019 Nov;63:106-114. [doi: 10.1016/j.sleep.2019.05.010] [Medline: 31610383]

119. Brief Infant Sleep Questionnaire (BISQ-R). Baby Sleep.: Pediatric Sleep Council URL: https://www.babysleep.com/BISQ/ L [accessed 2021-04-16]

120. Sadeh A. A brief screening questionnaire for infant sleep problems: validation and findings for an Internet sample. Pediatrics 2004 Jun;113(6):e570-e577. [doi: 10.1542/peds.113.6.e570] [Medline: 15173539]

121. Sadeh A, Mindell JA, Luedtke K, Wiegand B. Sleep and sleep ecology in the first 3 years: a web-based study. J Sleep Res 2009 Mar;18(1):60-73 [FREE Full text] [doi: 10.1111/j.1365-2869.2008.00699.x] [Medline: 19021850]

122. McDonald SW, Lyon AW, Benzies KM, McNeil DA, Lye SJ, Dolan SM, et al. The All Our Babies pregnancy cohort: design, methods, and participant characteristics. BMC Pregnancy Childbirth 2013;13(Suppl 1):S2. [doi:

$\underline{10.1186 / 1471-2393-13-s 1-s 2]}$

123. Brockway M, Benzies KM, Carr E, Aziz K. Breastfeeding self-efficacy and breastmilk feeding for moderate and late preterm infants in the Family Integrated Care trial: a mixed methods protocol. Int Breastfeed J 2018;13:29 [FRE Full text] [doi: 10.1186/s13006-018-0168-7] [Medline: 29989087]

124. World HO. Indicators for assessing infant and young child feeding practices: part 1: definitions: conclusions of a consensus meeting held 6-8 November 2007 in Washington DC, USA. 2008 Presented at: WHO Global Consensus Meeting on Indicators of Infant and Young Child Feeding; November 6-8, 2007; Washington DC, USA.

125. Faul F, Erdfelder E, Buchner A, Lang AG. Statistical power analyses using G*Power 3.1: tests for correlation and regression analyses. Behav Res Methods 2009 Nov;41(4):1149-1160. [doi: 10.3758/BRM.41.4.1149] [Medline: 19897823]

126. Children Vulnerable in Areas of Early Development: A Determinant of Child Health. Canadian Institute for Health Information. 2014. URL: https://yourhealthsystem.cihi.ca/hsp/inbrief\#!/indicators/013/

children-vulnerable-in-areas-of-early-development/:mapC1;mapLevel2;/ [accessed 2021-04-16]

127. Research Advancement through Cohort Cataloguing and Harmonization (ReACH). Maelstrom. URL: https://www. maelstrom-research.org/network/reach [accessed 2021-04-16]

\author{
Abbreviations \\ ACEs: Adverse Childhood Experiences \\ ASQ-3: Ages and Stages Questionnaire, Third Edition \\ ASQ: SE-2: Ages and Stages Questionnaire: Social-Emotional, Second Edition \\ BISQ-R: Brief Infant Sleep Questionnaire-Revised \\ CD-RISC 2: Connor-Davidson Resilience Scale \\ CSI-4: 4 -item Couple Satisfaction Index \\ EDS: Everyday Discrimination Scale \\ EPDS: Edinburgh Postnatal Depression Scale \\ GLTEQ: Godin-Shephard Leisure-Time Exercise Questionnaire \\ IBQ-R: Infant Behavior Questionnaire-Revised \\ ISEL: Interpersonal Support Evaluation List \\ IUS: Intolerance of Uncertainty Scale \\ PdP: Pregnancy During the COVID-19 Pandemic
}


PRAMS: Pregnancy Risk Assessment Monitoring System

PRAQ: Pregnancy Related Anxiety Questionnaire (English)

PRAQ-R2: Pregnancy Related Anxiety Questionnaire-Revised 2 (French)

PROMIS: Patient-Reported Outcomes Measurement Information System

PSS: Perceived Stress Scale

REDCap: Research Electronic Data Capture

SARS: severe acute respiratory syndrome

SCS-SF: Self-Compassion Scale-Short Form

SSEQ: Social Support Effectiveness Questionnaire

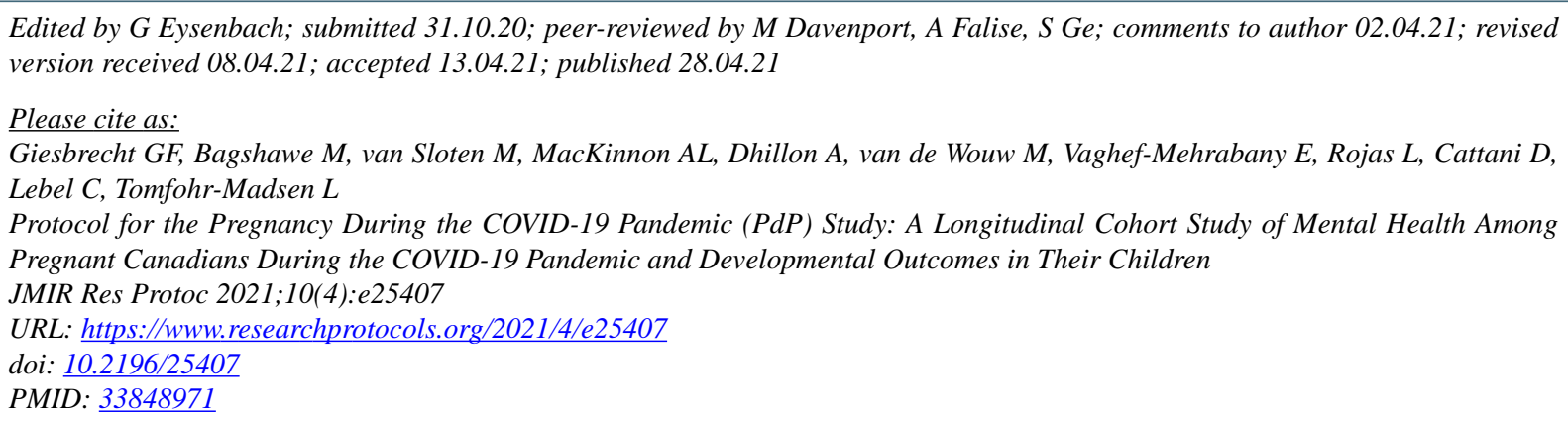

(C) Gerald F Giesbrecht, Mercedes Bagshawe, Melinda van Sloten, Anna L MacKinnon, Ashley Dhillon, Marcel van de Wouw, Elnaz Vaghef-Mehrabany, Laura Rojas, Danielle Cattani, Catherine Lebel, Lianne Tomfohr-Madsen. Originally published in JMIR Research Protocols (https://www.researchprotocols.org), 28.04.2021. This is an open-access article distributed under the terms of the Creative Commons Attribution License (https://creativecommons.org/licenses/by/4.0/), which permits unrestricted use, distribution, and reproduction in any medium, provided the original work, first published in JMIR Research Protocols, is properly cited. The complete bibliographic information, a link to the original publication on https://www.researchprotocols.org, as well as this copyright and license information must be included. 